\title{
A U-Shaped Slot UWB Antenna with Flexible and Wide Tunable Dual Notch Band
}

\author{
Zhongmin Zhang and Yongchang Sun \\ College of Information and Communication Engineering, Harbin Engineering University, Harbin, China
}

\begin{abstract}
A coplanar waveguide (CPW) fed ultra-wideband (UWB) antenna with flexible and wide tunable dual bandnotched characteristics is proposed in this paper. The dual band-notched function is achieved by using an U-shaped slot inserted into the ellipse radiation patch and by using an elliptic parasitic slit placed near the ground plane. The wide tunable band-notched characteristic is implemented by adjusting the length of $U$-shaped slot and by adjusting the length of ellipse parasitic slit. The design aims to achieve wide reconfigurable band-notched features on the UWB antenna. The simulated results indicate that the proposed antenna has a wide bandwidth (VSWR under 2) from $2.9 \mathrm{GHz}$ to $12.6 \mathrm{GHz}$ with fractional bandwidth of $125 \%$, and has a wide tunable notch band center frequency from $4.5 \mathrm{GHz}$ to $12.4 \mathrm{GHz}$.
\end{abstract}

Keywords. Ultra-wideband; slot antenna; notch band; wide tunable; U-shaped

\section{Introduction}

In recent years, the attention on ultra-wideband (UWB) communication technology has been increasing due to the Federal Communication Commission (FCC) allocated the UWB spectrum from $3.1 \mathrm{GHz}$ to $10.6 \mathrm{GHz}$ [1]. UWB communication has many advantages, such as wide bandwidth, high data rate wireless transmission, low power consumption, and so on [2]. However, in such a wide UWB frequency spectrum, there are several narrow-band systems like wireless local area network (WLAN) working at 5.15$5.825 \mathrm{GHz}$, ITU $8 \mathrm{GHz}$ band operating at $7.725-8.275 \mathrm{GHz}$, WiMAX system operating at $3.3-3.7 \mathrm{GHz}$, HIPERLAN/2 in Europe working at $5.15-5.725 \mathrm{GHz}, \quad \mathrm{X}$-band satellite communication links operating at $7.9-8.4 \mathrm{GHz}$ [1] [3] [4]. These narrow-band signals may interference with UWB communication system. To avoid the interference from other nearby frequency, UWB communication systems need a notch band function. The solution mainly has the following points. One is add some band-stop filter components [5], but this method increase the complexity of the system. The other one is using the antenna which integrated many bandnotched techniques. Such as electromagnetic band gaps (EBG) [6], T-shaped (tree-like) elements [7], band-rejected slot in feed line [8], rectangular slot [9], parasitic slits [10], L-shaped slots [11] and Ring-Resonator slot [12]. However, these antennas mostly aimed at certain frequencies, such as
WLAN or WiMAX, and cannot achieve a wide range of adjustments to reconfigure the notch band.

With the development of science and technology, more and more in narrow-band communication systems may join in the band of $3.1 \mathrm{GHz}$ to $10.6 \mathrm{GHz}$. In order to avoid these potential interference, reconfigurable become another notable direction of UWB antenna design, which can be used as single band-notched, dual band-notched, or completely as the normal UWB antenna. Most of these antennas used to adjust the corresponding ideal switch, to achieve a wide tunable notch frequency [7], [13]-[15]. But, these antennas have a complex structure, which is hard to adjust or fabricate. One effective way is designing a wide range adjustment antenna with simple structure, so we can adjust the performance of the antenna conveniently.

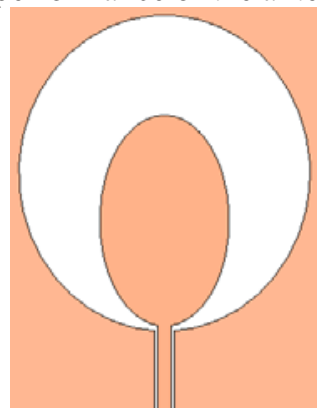

(a) Antenna-1

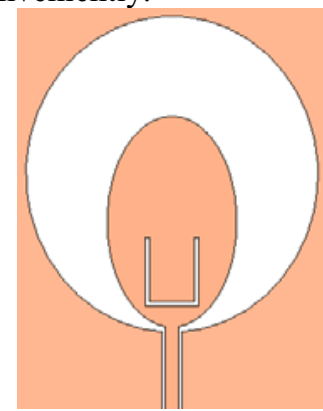

(b) Antenna-2 


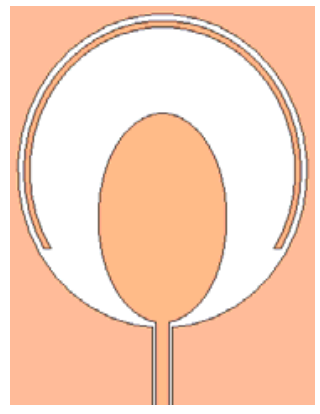

(c) Antenna-3

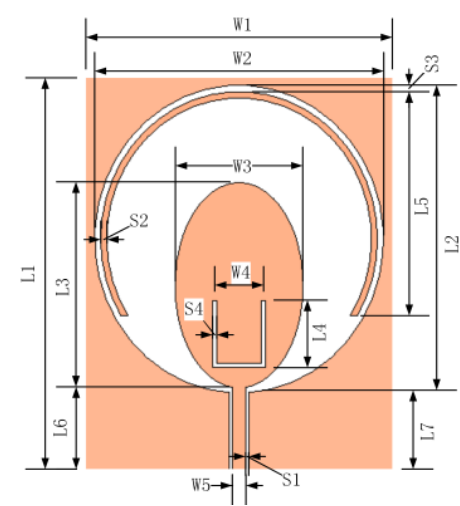

(d) Antenna-4
Figure 1. Proposed antenna geometry and design evolution

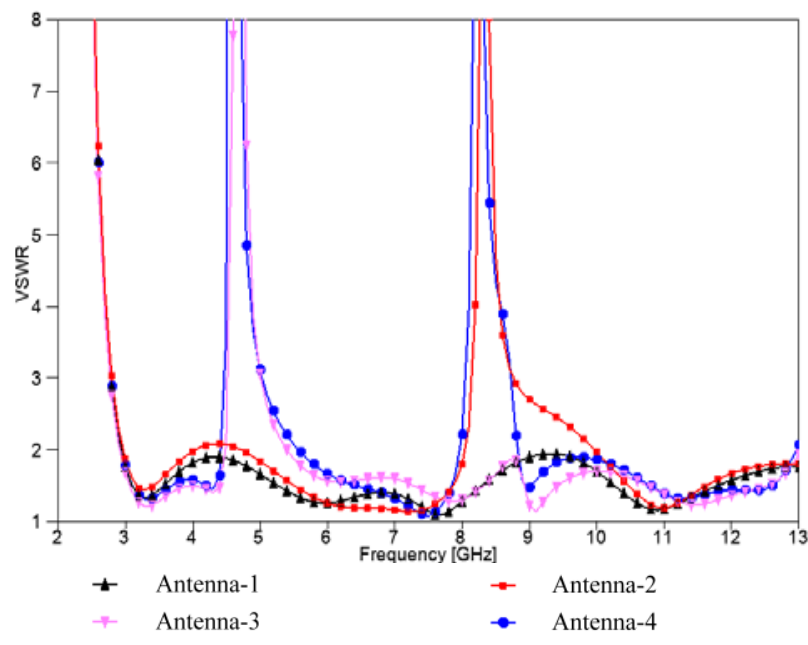

Figure 2. Four antennas band-notched characteristic

In this paper, we propose a simple structure and low-cost coplanar waveguide (CPW) fed ultra-wide band (UWB) antenna with a wide range tunable dual notch band. The dual band-notched function is implemented by inserting an Ushaped slot inside the ellipse radiation patch and by using an elliptic parasitic slit placed beside the ground plane. The center frequencies of these notch bands can be tuned by adjusting the length of the U-shaped slot and the elliptic parasitic slit. It is observed from simulated results that the proposed UWB antenna could operate on $2.9 \mathrm{GHz}$ to $12.6 \mathrm{GHz}$ with the VSWR less than 2 , and the notch bands center frequency could be adjusted from $4.5 \mathrm{GHz}$ to $12.4 \mathrm{GHz}$. In addition, the proposed antenna can also be used as a single notch band UWB antenna or normal UWB antenna by removing the U-shaped slot or elliptic parasitic slit, without use any switch, which can achieve a wide stop-band adjusting range. Therefore, the designed antenna has simple structure, wide tunable dual notch band, omnidirectional radiation patterns, small size $(30.6 \mathrm{~mm} \times 23 \mathrm{~mm})$, and easy reconfigurable functions, which makes it very suitable for UWB communication system. The details of the design procedure and the performance of the proposed antenna are described in the following sections.

\section{Antenna design}

The geometry and design evolution of proposed UWB antenna is displayed at Figure 1. First of all, an UWB basic antenna without U-shaped slot and elliptic parasitic slit is illustrated in Fig. 1(a) and represented as Antenna-1. This antenna contains an elliptic slot etched near the ground plane, an ellipse radiation element, and a $50 \mathrm{Ohm} \mathrm{CPW-fed}$ structure. The relative dielectric constant and loss tangent of $1.6 \mathrm{~mm}$ thickness substrate is 2.65 and 0.002 , respectively. The CPW-fed structure contains a transmission line with a gap between the feed-line and the ground plane is $\mathrm{S} 1=$ $0.2 \mathrm{~mm}$, and the width of transmission line is $\mathrm{W} 5=1 \mathrm{~mm}$.

To achieve band-notched functions, U-shaped slot is inserted in ellipse radiation patch, as shown in Fig. 1(b) and elliptic parasitic slit is placed beside the ground plane, as shown in Fig. 1(c). These antennas are both single bandnotched topologies which are denoted as Antenna-2 and Antenna-3, respectively. In order to implement the dual band-notched feature, U-shaped slot and elliptic parasitic slit are both employed to obtain two band-stop characteristic in the meanwhile. The proposed antenna is shown in Fig. 1(d), and defined as Antenna-4.

By adjusting the length of the U-shaped slot and the elliptic parasitic slit, we can control the center frequency of two notch bands independently. In the design, one notch band which operating at $5 \mathrm{GHz}$ WLAN band, is realized by placing the elliptic parasitic slit, we can tune this notch band center frequency by changing the length of L5, and the other stop band to prevent the interference from the $\mathrm{X}$ band application which operating at $7.9-8.8 \mathrm{GHz}$, is achieved by inserting the U-shaped slot to the ellipse radiation patch, we can tune this notch band center frequency by modifying the length of L4. The notch band adjustment does not affect each other.

A full-wave simulation solver, High Frequency Structure Simulator (HFSS), is used to model the antenna and give the simulation results. The proposed antenna optimized parameters are shown below: L1 $=30.6 \mathrm{~mm}, \mathrm{~W} 1=23 \mathrm{~mm}$, $\mathrm{L} 2=24 \mathrm{~mm}, \mathrm{~W} 2=21.6 \mathrm{~mm}, \mathrm{~L} 3=16 \mathrm{~mm}, \mathrm{~W} 3=9.6 \mathrm{~mm}, \mathrm{~L} 4=$ $5.4 \mathrm{~mm}, \mathrm{~W} 4=4 \mathrm{~mm}, \mathrm{~L} 5=17.5 \mathrm{~mm}, \mathrm{~W} 5=1 \mathrm{~mm}, \mathrm{~L} 6=6.4 \mathrm{~mm}$, $\mathrm{L} 7=6 \mathrm{~mm}, \mathrm{~S} 1=0.2 \mathrm{~mm}, \mathrm{~S} 2=0.5 \mathrm{~mm}, \mathrm{~S} 3=0.5 \mathrm{~mm}, \mathrm{~S} 4=$ $0.3 \mathrm{~mm}$.

\section{Notch band characteristic}

We analyze the notch band characteristic of the proposed antenna by HFSS in this section. Fig. 2 shows the standingwave ratio (VSWR) of four antennas mentioned above. We can find that the band-notched performance of these antennas is an obvious difference. For antenna-1, there is no U-shaped slot and no elliptic parasitic slit, which has a bandwidth of $9.7 \mathrm{GHz}$ without any notch band. It can be used as fundamental UWB antenna which covers all UWB band. The antenna-2 is based on the antenna-1, increase a Ushaped slot in the radiation patch which makes it become a single band-notched antenna. The notch band is operating at $7.9-8.8 \mathrm{GHz}$. It is designed for preventing the interference from satellite communication $(7.9-8.4 \mathrm{GHz})$ and any other system which works within this band. The antenna-3 is also 
based on the antenna-1, place an elliptic parasitic slit near the ground plane. This antenna has single notch band features which operating at $4.5-5.8 \mathrm{GHz}$. This band stop function can be used for mitigating the interference from WLAN (5.15$5.825 \mathrm{GHz}$ ), $\mathrm{C}$ band system (part of $4.5-5 \mathrm{GHz}$ ), and so on. The antenna- 4 inherited the merit of the antenna- 2 and antenna-3, makes it becomes a dual band-notched UWB antenna.

The simulation results, as shown in Fig. 3, demonstrate the current distribution of each antenna. The Fig. 3(a) and Fig. 3(b) display the current distributions of antenna-2 which operates at $4.8 \mathrm{GHz}$ and $8.2 \mathrm{GHz}$, respectively. In this case, the current at $4.8 \mathrm{GHz}$ is working normally but the current at $8.2 \mathrm{GHz}$ concentrates on the U-shaped slot which consumes a lot of energy. While the Fig. 3(c) and (d) are indicate that the elliptic parasitic slit of antenna-3 consumes a large of energy at $4.8 \mathrm{GHz}$ but $8.2 \mathrm{GHz}$ works well. Fig. $3(\mathrm{e})$ and (f) illustrate the current distribution of antenna- 4 at $4.8 \mathrm{GHz}$ and $8.2 \mathrm{GHz}$. We can find that the current of $4.8 \mathrm{GHz}$ and $8.2 \mathrm{GHz}$ are both

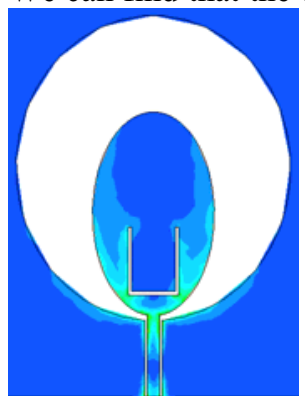

(a) Antenna-2 at $4.8 \mathrm{GHz}$

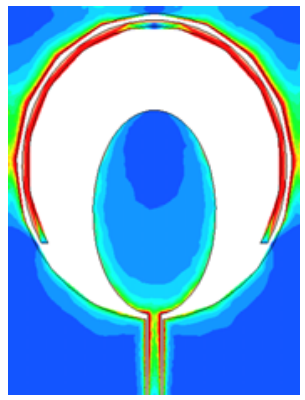

(c) Antenna-3 at $4.8 \mathrm{GHz}$

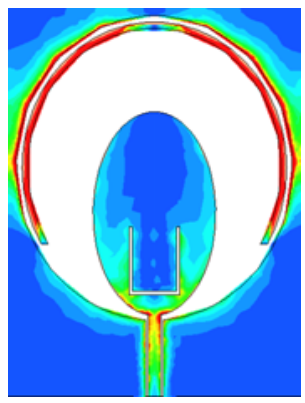

(e) Antenna-4 at $4.8 \mathrm{GHz}$

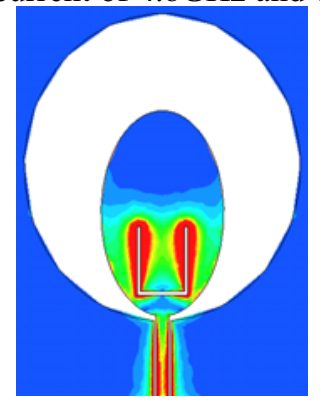

(b) Antenna-2 at $8.2 \mathrm{GHz}$

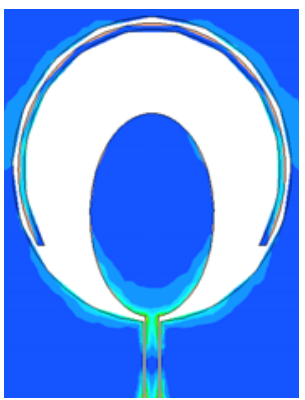

(d) Antenna-3 at $8.2 \mathrm{GHz}$

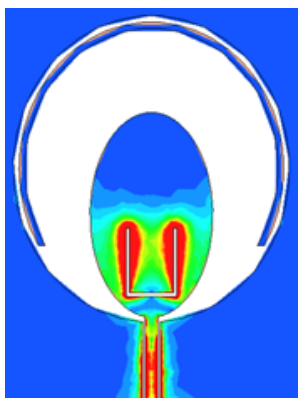

(f) Antenna-4 at $8.2 \mathrm{GHz}$
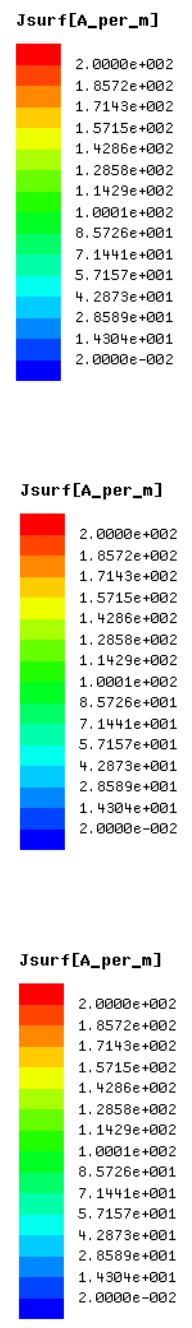

$0000 e-002$
Figure 3. Current distribution on corresponding frequency of each antenna notched by elliptic parasitic slit and U-shaped slot. Compare with the results of the above, we can also be found that the stop-band performance of antenna-4 is almost equal to the superposition of the antenna- 2 and antenna-3, in other words, they can work together and not affect each other.

Combined with Fig. 2 and Fig. 3, we can make a conclusion that the antenna-4 has two notch band both 4.5$5.8 \mathrm{GHz}$ and $7.9-8.4 \mathrm{GHz}$, which the U-shaped slot contribute to the higher notch band and the elliptic parasitic silt lead to the lower notch band, and these notch band can work independently. Therefore, the antenna- 4 can reduce all of the potential interference mentioned above. Besides, the single notch band UWB antenna can be obtained by removed the U-shaped slot or elliptic parasitic slit from antenna-4 and the procedure of reconfigure antenna- 4 as a conventional UWB antenna is the same.

\section{Parametric effects}

In this section, we will study the influence of various

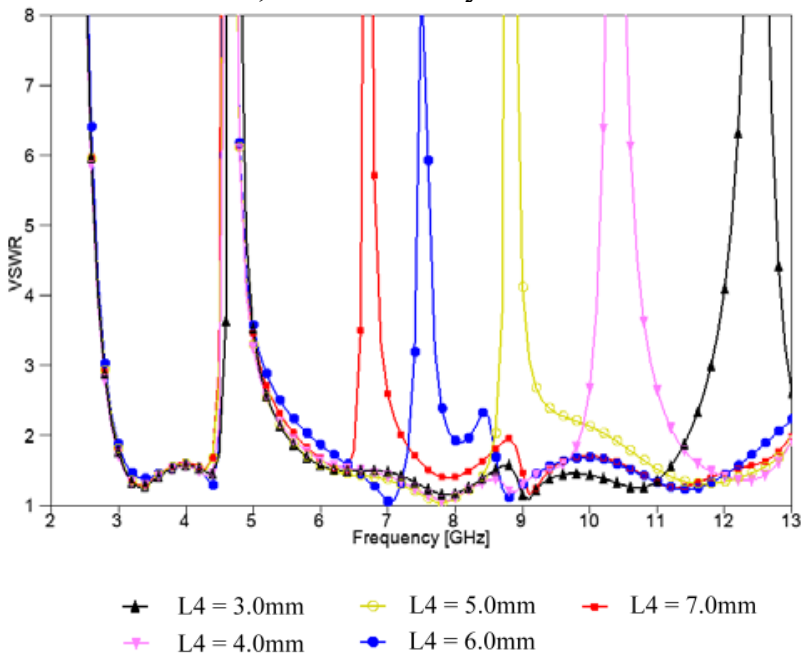

Figure 4. Effects of L4

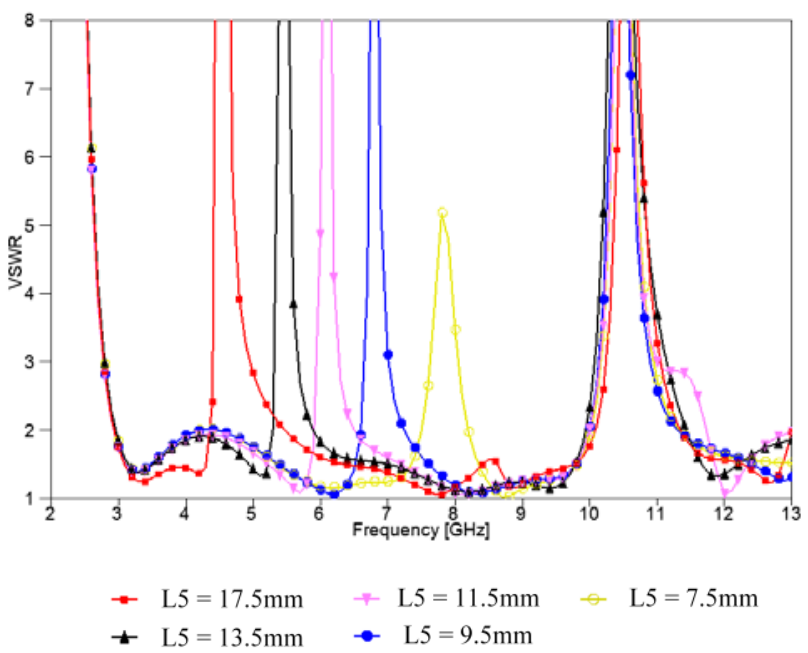

Figure 5. Effects of L5 
antenna parameters on the stop-band characteristics. The HFSS is employed to obtain the simulation results and all the simulation target is antenna-4. Fig. 4 shows the effects of varying L4. We can see that the parameter L4 has a great influence on the higher stop band. With the length of the L4 increasing, the center frequency of the higher notch band moves to low frequency and the bandwidth of the notch band is reduced, while the lower notch band hardly changes. The higher notch band can be tuned from $6.6 \mathrm{GHz}$ to $12.4 \mathrm{GHz}$, which is a very large tunable range. This is because the varying L4 can largely adjust the total length of the U-shaped slot, which also increases the current path along the Ushaped slot in a wide tunable range. We can adjust it to prevent the potential interference like ITU $8 \mathrm{GHz}$ band application, satellite communication system, $\mathrm{X}$ band system, and any other narrow band systems which operating from 6.6-12.4GHz. The effects of varying L5 are shown in Fig. 5. With the increasing of L5, the center frequency of higher notch band and the bandwidth of the notch band are both changed slightly, while the center frequency of lower notch band moves to low frequency obviously. Thus, the varying L5 is also a key factor, same as L4, influencing the corresponding notch band center frequency, which can be tuned from $4.5 \mathrm{GHz}$ to $8.3 \mathrm{GHz}$. This range covers

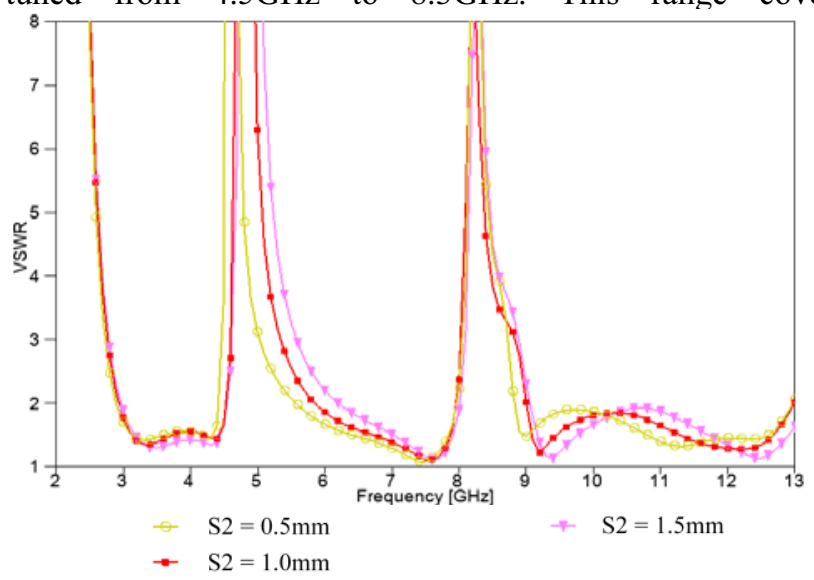

Figure 6. Effects of S2

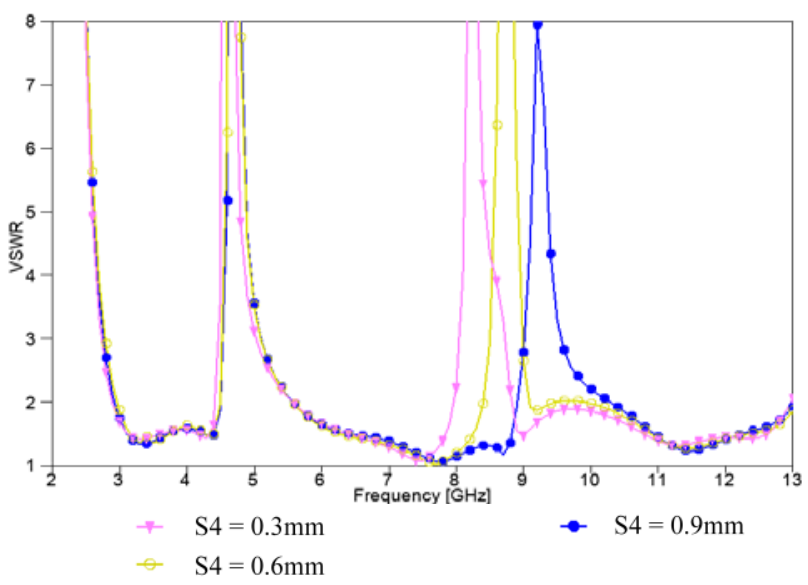

Figure 8. Effects of S4
HIPERLAN/2 (5.15-5.725GHz), WLAN (5.15-5.825GHz) and also covers ITU $8 \mathrm{GHz}$ band $(7.725-8.275 \mathrm{GHz})$. Fig. 6 shows the effects of varying S2. With the increment of S2, the center frequency is few changed both lower notch band and higher notch band, but the bandwidth of lower notch band is expanded. The effects of varying S3 are demonstrated in Fig. 7. It is indicated that the center frequency of lower notch band moves to high frequency and the bandwidth of lower notch band is reduced and the bandwidth of higher notch band is increased with the increment of S3. The reason is that the increased S3 has influence on the total length of the elliptic parasitic slit, and also affect the coupling between ground plane and elliptic parasitic slit. Besides, adjusting S3 can also alter the coupling between radiation patch and elliptic parasitic slit. Thus, we can find that the bandwidth of higher notch band caused by U-shaped slot is also changed slightly. Fig. 8 describes the effects of S4. With the increment of S4, the center frequency of higher notch band moves to high frequency and the lower notch band is not changed. The effects of varying W4 are displayed in Fig. 9. It can be seen that the center frequency of higher notch band is decreased with the increment of W4. In addition, the bandwidth of higher notch band is also improved because of increasing

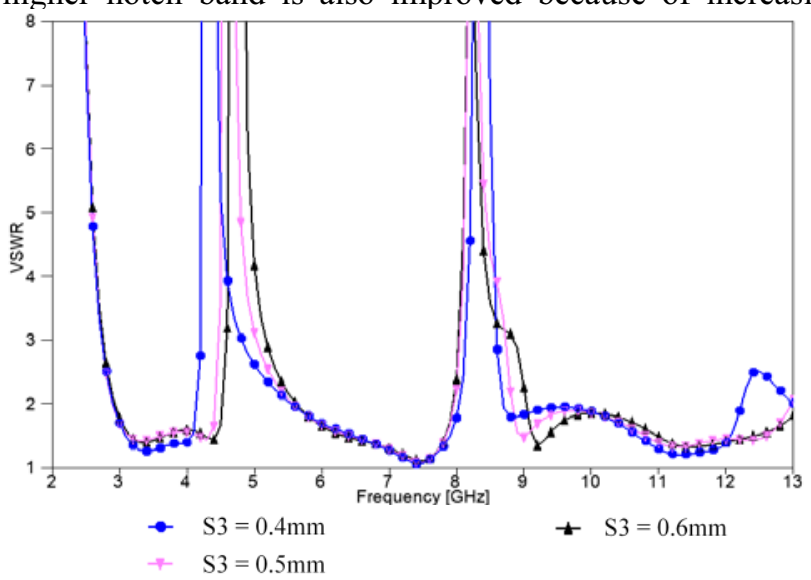

Figure 7. Effects of $\mathrm{S} 3$

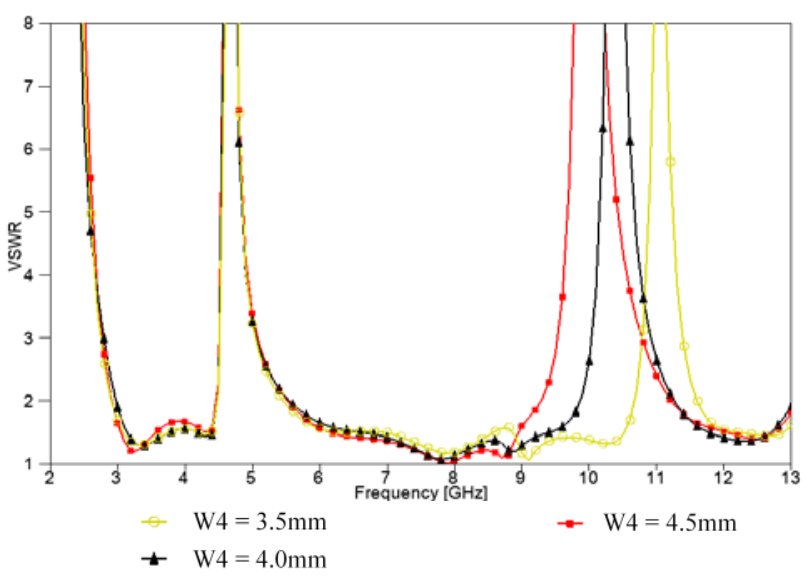

Figure 9. Effects of W4 
W4 not only change the resonance length of the U-shaped slot but also alter the distributive capacitance and distributive inductance among two parallel branches of the U-shaped slot.

From what has been discussed above, the major parameters that affect the stop band center frequency are L4 and L5, and the major parameters that affect the bandwidth of corresponding notch band are S2 and W4. We do not recommend adjusting S3 and S4 because either the tuned results are not very obviously, can be replaced by other parameters or these parameters can cause some uncertainly effects, which had been displayed in Fig. 7, 12-13GHz.

\section{Radiation}

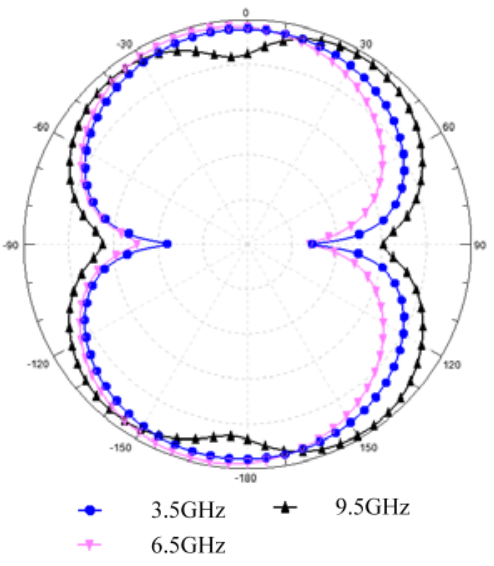

(a) X-Z plane

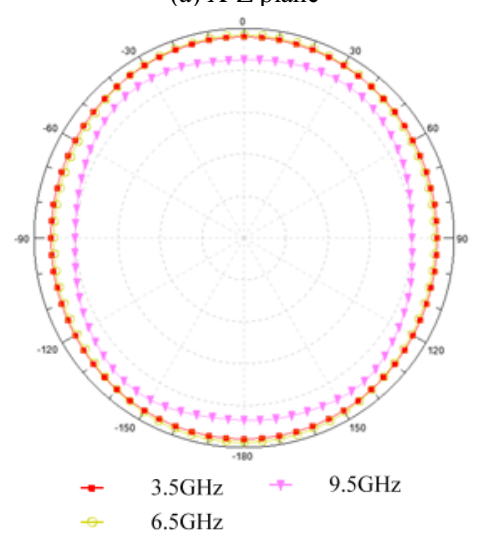

(b) Y-Z plane

Figure 10. Radiation patterns of antenna-4

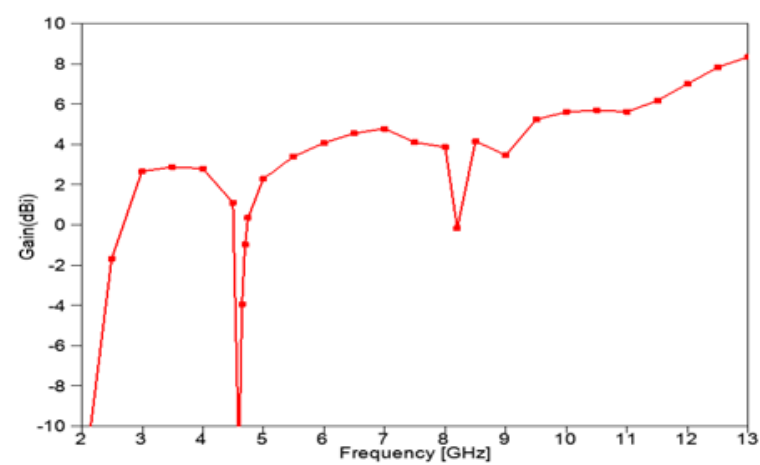

Figure 11. Peak gain of antenna-4
The radiation patterns of the antenna- 4 at $3.5 \mathrm{GHz}$, $7.5 \mathrm{GHz}$ and $11.5 \mathrm{GHz}$ are demonstrated in Fig. 10. We can see that the proposed antenna has a good omnidirectional radiation characteristic in the $\mathrm{Y}-\mathrm{Z}$ plane and monopole-type radiation characteristics in the $\mathrm{X}-\mathrm{Z}$ plane. Despite the slight deterioration at higher frequency, which is caused by inserting the U-shaped slot to the radiation patch, the proposed antenna still has good omnidirectional radiation characteristics. Fig. 11 illustrates the peak realized gain with frequency for the designed antenna over UWB spectrum range $(2-13 \mathrm{GHz})$. It can be seen that, as discussed above, the peak gains of two notch bands which operating at $4.5 \mathrm{GHz}$ and $8.2 \mathrm{GHz}$ are dropped, and decrease about $-10.2 \mathrm{dBi}$ in the lower notch band and about $-0.3 \mathrm{dBi}$ in the higher notch band. Besides, following the higher notch band, we can see the gain has a little drop, but the gain in this wave trough is still greater than $2 \mathrm{dBi}$. Therefore, the little mismatch is not enough to affect the normal work of the proposed antenna.

\section{Conclusion}

In this paper, we designed a simple, low cost, and wide tunable dual notch band UWB antenna. The wide adjustable stop bands are realized by U-shaped slot and elliptic parasitic slit, respectively. These notch bands work independently, and we can adjust the notch band features by some parameters. For the center frequency of these notch bands, we can change the parameter L4 and L5 to achieve a wide tunable range. For the bandwidth of these notch bands, we can control the parameter S2 and W4 to obtain a proper bandwidth. In addition, the proposed antenna can also be reconfigurable as a single notch band antenna or a conventional UWB antenna by removing the U-shaped slot or the elliptic parasitic slit. Besides, the proposed antenna has omnidirectional radiation pattern, and the peak gain also indicates the good performance of the proposed antenna.

\section{Acknowledgment}

This paper is funded by the International Exchange Program of Harbin Engineering University for Innovationoriented Talents Cultivation and this paper is also supported by National Nature Science Fund of China (No. 61101141), the authors wish to thank for these supports.

\section{References}

1. D. Sarkar, K. V. Srivastava, and K. Saurav, "A Compact Micro strip-Fed Triple Band-Notched UWB Monopole Antenna," IEEE Antennas and Wireless Propag. Lett., vol. 13, pp. 396-399, 2014.

2. Z. H. Tu, W. A. Li, and Q. X. Chu, "Single-Layer Differential CPW-Fed Notch-Band Tapered-Slot UWB Antenna," IEEE Antennas and Wireless Propag. Lett., vol. 13, pp. 1296-1299, 2014.

3. R. Azim, M. T. Islam, and A. T. Mobashsher, "Dual Band-Notch UWB Antenna With Single Tri-Arm 
Resonator," IEEE Antennas and Wireless Propag. Lett., vol. 13, pp. 670-673, 2014.

4. C. T. Chuang, T. J. Lin, and S. J. Chung, "A BandNotched UWB Monopole Antenna With High NotchBand-Edge Selectivity," IEEE Trans. Antennas and Propag., vol. 60, No. 10, pp. 4492-4499, Oct. 2012.

5. B. Mohammadi, A. Valizade, P. Rezaei, and J. Nourinia, "New design of compact dual band-notch ultra-wideband bandpass filter based on coupled wave canceller inverted T-shaped stubs," IET Microw. Antennas Propag., vol. 9, lss. 1, pp. 64-72, Aug. 2014.

6. H. A. Majid, M. K. A. Rahim, M. R. Hamid, N. A. Murad, and A. Samsuri, "Reconfigurable Band Notch UWB Antenna using EBG Structure," presented at the IEEE Asia-Pacific Conference on Applied Electromagnetics, Johor, Malaysia, December 8-10, 2014.

7. M. Naser-Moghadasi, R. A. Sadeghzadeh, T. Sedghi, T. Aribi, and B. S. Virdee, "UWB CPW-Fed Fractal Patch Antenna With Band-Notched Function Employing Folded T-shaped Element," IEEE Antennas and Wireless Propag. Lett., vol. 12, pp. 504-507, 2013.

8. F. Zhu, S. Gao, A. TS Ho, R. A. Abd-Alhameed, C. H. See, T. W C Brown, J. Li, G. Wer, and J. Xu, "Multiple Band-Notched UWB Antenna With BandRejected Elements Integrated in the Feed Line," IEEE Trans. Antennas and Propag., vol. 61, No. 8, pp. 39523960, Aug. 2013.

9. M. Ojaroudi, and N. Ojaroudi, "Ultra-wideband Small Rectangular Slot Antenna With Variable Band-Stop Function," IEEE Trans. Antennas and Propag., vol. 62, No. 1, pp. 490-494, Jan. 2014.
10. R. Azim, M. T. Islam, A. T. Mobashsher, "Design of a Dual Band-Notch UWB Slot Antenna by Means of Simple Parasitic Slits," IEEE Antennas and Wireless Propag. Lett., vol. 12, pp. 1412-1415, 2013.

11. J. W. Wang, J. Y. Pan, X. N. Ma, and Y. Q. Sun, "A Band-Notched UWB Antenna With L-Shaped Slots and Open-Loop Resonator," in Proc. of 2013 IEEE International Conf. on Applied Superconduc-tivity and Electromagnetic Devices, Beijing, 2013, pp. 312-315.

12. K. D. Xu, Y. H. Zhang, R. J. Spiegel, Y. Fan, W. T. Joines, and Q. H. Liu, "Design of a Stub-Loaded RingResonator Slot for Antenna Application," IEEE Trans. Antennas and Propag., vol. 63, No. 2, pp. 517-524, Feb. 2015.

13. Y. S. Li, W. X. Li, and Q. B. Ye (October 2013). A CPW-Fed Circular Wide-Slot UWB Antenna with Wide tunable and Flexible Reconfigurable Dual Notch Bands. The Scientific Word Journal [Online]. Volume 2013, Article ID: 402914, 10 pages. Available: http://dx.doi.org/10.1155/2013/402914

14. Y. S. Li, W. X. Li, "A Circular Slot Antenna with Wide Tunable and Reconfigurable Frequency Rejection Characteristic Using Capacitance Loaded Split-Ring Resonator for UWB Applications," Wireless Personal Commu., vol. 78(1), pp. 137-149, Mar. 2014.

15. D. Zhao, L. Lan, Y. Han, F. Liang, Q. Zhang, and B. Z. Wang, "Optically Controlled Reconfigurable BandNotched UWB Antenna for Cognitive Radio Applications," IEEE Photonics Tech. Letters, vol. 26, No. 21, pp. 2173-2176, Nov 2014. 